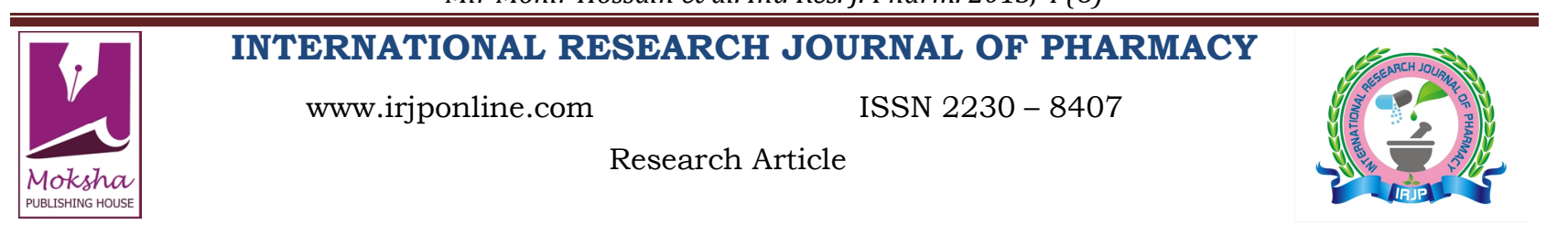

\title{
ASSESSMENT OF INFLUENCING FACTORS ON PRESCRIPTION PRACTICES OF PHYSICIANS IN BANGLADESH
}

\author{
Mir Monir Hossain ${ }^{1 *}$, Sumaiya Kawsar ${ }^{2}$, Tasmuna Tamrin Tanmy ${ }^{2}$ and Abu Yousuf ${ }^{3}$ \\ ${ }^{1}$ Assistant Professor, Department of Pharmacy, University of Science and Technology Chittagong (USTC), Foy's Lake, \\ Chittagong, Bangladesh \\ ${ }^{2}$ Students of Master of Pharmacy (M. Pharm), Department of Pharmacy, University of Science and Technology Chittagong \\ (USTC), Foy's Lake, Chittagong, Bangladesh \\ ${ }^{3}$ General Physician, Department of Forensic Medicine, BGC Trust Medical College, Chittagong, Bangladesh \\ *Corresponding Author Email: monir_pharm@yahoo.com
}

Article Received on: 10/06/13 Revised on: 08/07/13 Approved for publication: 11/08/13

DOI: $10.7897 / 2230-8407.04819$

IRJP is an official publication of Moksha Publishing House. Website: www.mokshaph.com

(C) All rights reserved.

\section{ABSTRACT}

In Bangladesh same drug molecules are sold under different brand names by different pharmaceutical companies. To persuade the physicians to prescribe their brands pharmaceuticals engage in marketing techniques like giving samples, gifts, sponsoring travel etc. Many countries are striving to reduce the impact of incentives on prescription behavior. This study explores the influence of factors on the prescription practices of doctors in Bangladesh. Data collection was done by a self administered questionnaire. This document outlines the research works holds the initial research finding out the factors that literally affect the drugs and medicines that goes written in a prescription. Five fully dedicated groups of people were engaged for conducting the survey efficiently without any bias. The survey required four months of time to come for an end. The reflection and feedback we received from this project, is completely the picture of whole Bangladesh.

Keywords: Prescription, physician, representatives, factors.

\section{INTRODUCTION}

Prescribing is one of the most important roles of a physician because medication is one of the most frequent ways of treating illness. A prescription $\left(\mathrm{R}_{\mathrm{X}}\right)$ is a health-care programme that governs the plan of care for an individual patient and is implemented by a qualified practitioner. In the last few years the relations between the physicians and pharmaceutical companies have received considerable attention $^{1,2}$. Physicians are privileged with the right of recognizing the need of their patients and recommend medications for the well-being of their patients. Hence, the relation between the physician and pharmaceutical companies may create a conflict between the ethical professional interest of a doctor and his financial self-interest. The increase in incentives to attract the doctor's prescription behavior reflects as a rise in the price of prescription medicines. The pharmaceuticals resort to many ways in marketing their product. Giving away gifts, free lunches, sponsoring education and holidays have all been criticized as inducements which compel a doctor to prescribe without scientific basis ${ }^{3}$. A study from Canada showed that the association with pharmaceuticals leads to less than appropriate prescribing behavior by the doctor ${ }^{4}$. Many physicians, however, do not feel that their prescriptions are influenced by gifts and other incentives provided by pharmaceuticals ${ }^{5}$. What is the ethical acceptability of physicians receiving gifts from drug companies? Large industry gifts are considered as inducements while small gifts such as pens, paperweights and note pads, considered acceptable by many. Evidence from social science research suggests that gifts of negligible value can influence the behavior of the recipient and the recipient may not always realize this ${ }^{6}$. More than eighty percent of physicians see drug representatives or sales personnel regularly ${ }^{2}$. Studies in China $^{5}$ and Australia ${ }^{7}$ showed that sales personnel do not significantly affect a doctor's prescription behavior. One of the disadvantages of these studies, which depended on the responses of the physicians, is the possibility of "faking good bias" ${ }^{\prime 8}$ which is a tendency among responders to give socially desirable responses to questions relating to one's behavior. These trends have raised the concern that pharmaceutical companies might have undue influence on the prescribing behavior of physicians. In particular, there is concern that a significant percentage of physicians might be prescribing a narrow range of heavily promoted drugs, or might be exclusively prescribing branded drugs to the detriment of patient welfare. However, empirical evidence on the prescribing behavior of physicians and its consequences for patients is limited. Some studies suggest that physicians' exhibit narrow prescribing behavior, particularly general practitioners, but much of this evidence is decade's old ${ }^{9-13}$. More recent work finds that the prescribing patterns of physicians are substantially more concentrated than the aggregate market in each class and that physicians differ in their preferred drug within a class ${ }^{14,15}$. There are no recently published studies that have addressed the factors that influence the prescription behavior of physicians in Bangladesh. This study aims to identify the factors that influence the prescription behavior of physicians in the choice of brands.

\section{MATERIALS AND METHODS}

Data collection was conducted by a self administered questionnaire. The places of Bangladesh covered under this research were carefully selected by first identifying the places where most patients gather for consult and treatment. Before going into field of practice, a survey plan and schedule were set ahead which sincerely followed and the target was successfully accomplished. The study subjects were from two categories: physicians and sales personnel. The sampling of physicians was done by stratified sampling. There were two strata of physicians: i) General practitioners (GPs), and ii) 
Specialists physicians (those with either DM or MCh degree). The sales personnel were also sampled similarly so that a fair distribution of field staff, middle level managers and supervisors were available. Five hundred (500) physicians response were recorded. Responder physicians include both general practitioners (GPs) as well as specialist doctors. Among them 180 were GPs and rest 320 were specialist doctors.

\begin{tabular}{|c|c|c|}
\hline $\begin{array}{c}\text { Physician } \\
\text { Category }\end{array}$ & $\begin{array}{c}\text { Number of responders } \\
\text { (In total 500 responders) }\end{array}$ & $\begin{array}{c}\text { Percent of } \\
\text { responders }\end{array}$ \\
\hline $\begin{array}{c}\text { General physicians } \\
(\mathrm{GPs})\end{array}$ & 180 & $36 \%$ \\
\hline $\begin{array}{c}\text { Specialist } \\
\text { physicians }\end{array}$ & 320 & $64 \%$ \\
\hline
\end{tabular}

A schedule was made for the convenience of meeting with the physicians. The schedule was entirely based on the time of availability of the physicians in hospitals, clinics and in their private chamber. The survey was conducted between August and November of 2012.

In the same way, we took carefully the responses of sales representatives of renowned pharmaceutical manufacturers to reflect the real views of prescription behavior of the physicians. In the way of accomplishing this research work, there were constraints like any other work. The constraints include: lack of human resources, lack of financial resources, time limitations and work load of physicians and obviously lack of interest of both physicians and sales people to response. But we tried of our best to perform our research work smoothly and effectively.

\section{RESULTS AND DISCUSSION}

The study subjects included both physicians and sales representatives. Five hundred (500) physicians response were recorded. Responder physicians include both general practitioners (GPs) as well as specialist doctors. Among them 180 were GPs and rest 320 were specialist doctors. The sales personnel surveyed included 100 field staffs and 25 managers. The questionnaires were assessed and calculated properly. The results can be presented by different figures and graphs that can be discussed as follows: The majority of doctors believed that information they receive from prescription drug company representatives was helpful to them, viewing the information as at least somewhat useful and accurate. Almost all physicians received perks from the sales representatives, with over 8 in 10 told that they received free drug samples. The majority of physicians knew that these drug company representatives receive information about their prescribing practices. When presented with three possible reactions to this profiling, physician expressed some discomfort but told they understood why the drug companies practiced that (61\%). However, about 7 in 100 told that they are strongly opposed to the collection and use of this information, while over 2 in 10 expressed the opposite view, said that they have no problem with this practice.

Few doctors thought that, the information from drug company representatives were "very useful" but the majority believed these was at least "somewhat useful" (Figure 1). In this case, $14 \%$ of doctors told that, informations from drug representatives were "very useful," and $72 \%$ told these were "somewhat useful."
When the physicians are asked for the accuracy of informations provided by the drug representatives then the majority of them believed that it the informations were "somewhat accurate" (Figure 2). In this case, $74 \%$ of doctors told that, informations from drug representatives was "somewhat accurate" and $16 \%$ told that "not very accurate".

Most physicians (84 \%) told that, they received free drug samples from a drug company representative (Figure 3). In this case, $2 \%$ physicians told that, they received free gifts, $5 \%$ told they received financial incentives, $5 \%$ responded for meal, free tickets or free travels and $2 \%$ told they received other in-kind benefits.

About $53 \%$ physicians realized that, drug industry representatives received information about their prescribing drugs, but around $44 \%$ were not aware about it (Figure 4).

When told drug companies profile to them, $27 \%$ doctors were most likely to say that, they were not entirely comfortable with this, but they understood why the companies collected the information (Figure 5). Here $61 \%$ of doctors chose the statement, "It bothers me, but I understand why they do it," about $7 \%$ expressed strong opposition to the practice, picking the statement, "It is unacceptable for them to collect and use this information" from the questionnaire.

When asked about whom physicians to expect as medical representative, $36 \%$ answered that, they expect pharmacists to come while $61 \%$ told they expect any science graduate to approach (Figure 6).

When physicians are asked for the types of drug name they like to prescribe then $66 \%$ physicians told they like to prescribe drugs in brand names and $33 \%$ answered that they like to write generic names of drugs in prescription (Figure 7).

In response to the question of how many medical promotional representatives visit physicians each day, the answers of physicians were varied. It is best to describe the number of medical promotional representatives in range. The range of number of medical representatives visited physicians was from minimum two (02) representatives to thirty (30) at maximum.

In the case of time spared by the physicians for medical promotional representatives, the range was from five (05) to one hundred and twenty (120) minutes per day.

\section{CONCLUSION}

This innovative study indicates that, a number of factors influencing the prescription habits of physicians in our country. The perk of pharmaceutical companies now a days have so strong impact on physicians that nearly two thirds of the practitioners $(66 \%)$ liked to write brand name of drugs on a prescription. This is clearly beneficial for the pharmaceutical companies but at the end of the run it affects the patients. People could have get treatment at lower cost if the prescriber intend more to prescribe drugs by generic name. 


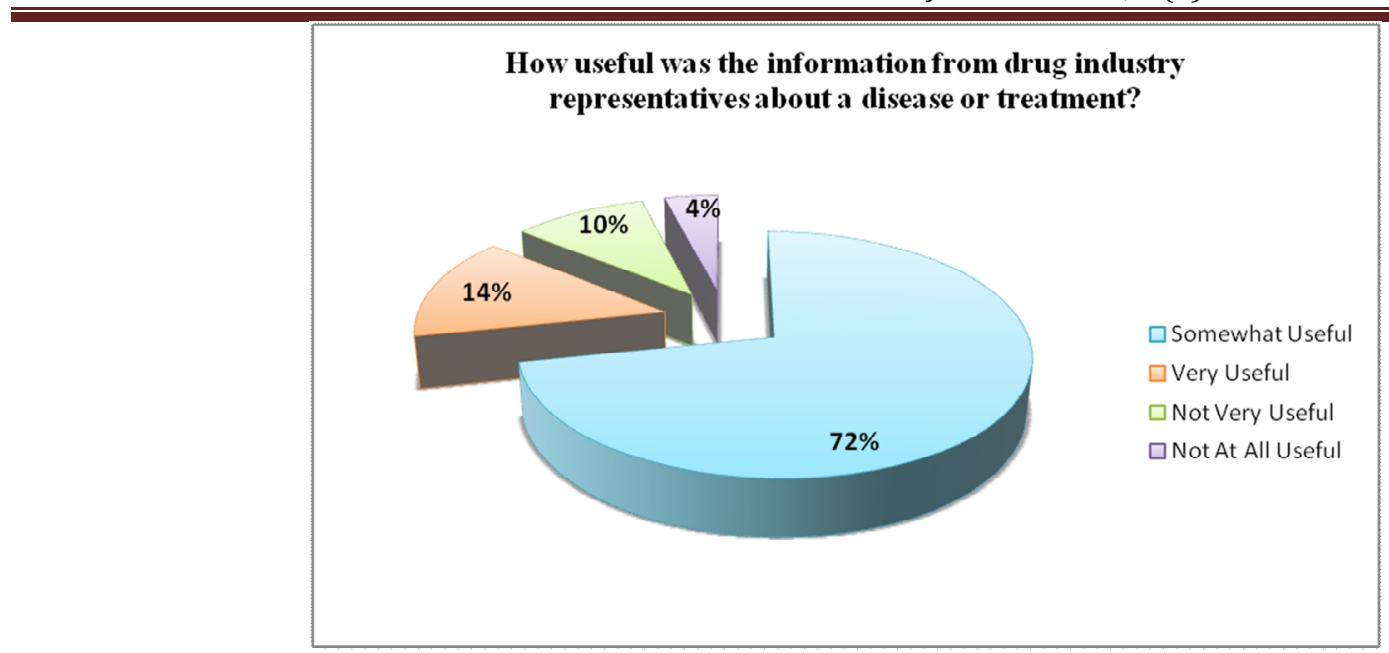

Figure 1: Usefulness of Information

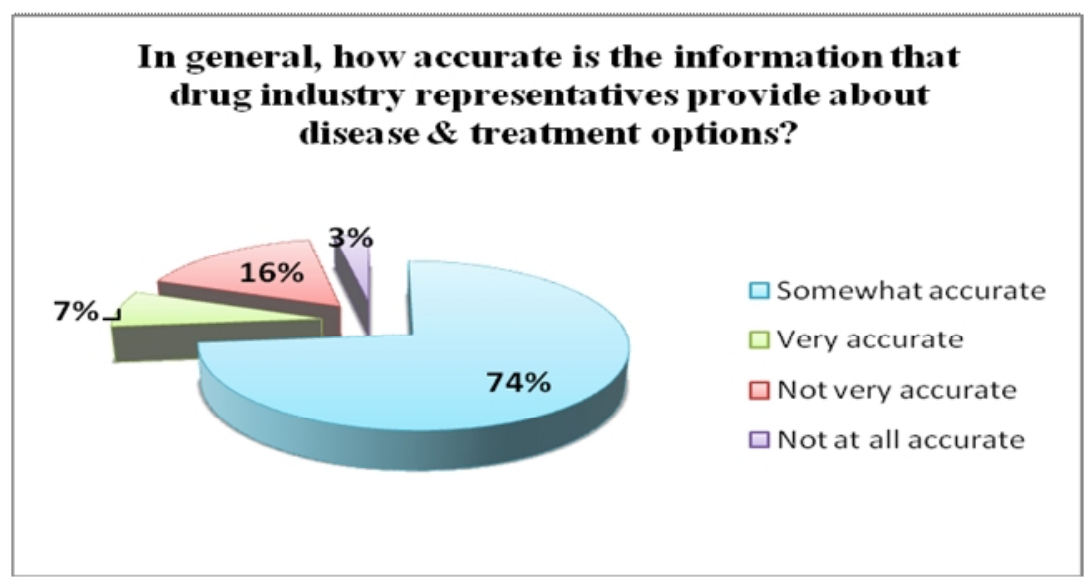

Figure 2: Accuracy of Information

\section{Have you ever accepted any kind of the following from a drug company representative?}

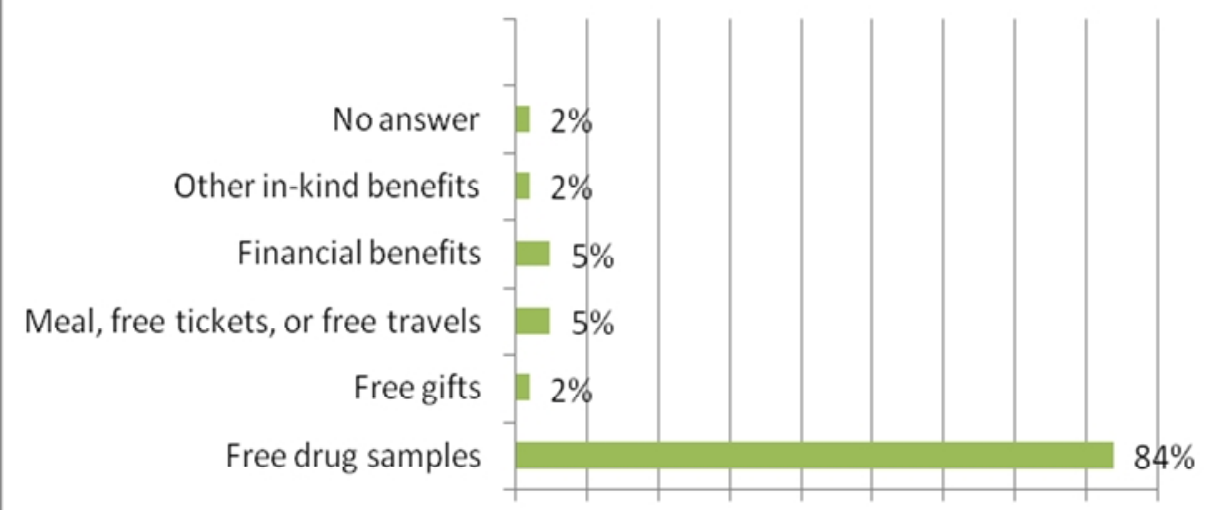

0\% $10 \%$ 20\% 30\% 40\% 50\% 60\% 70\% $80 \% 90 \%$

Figure 3: Perks from Companies 


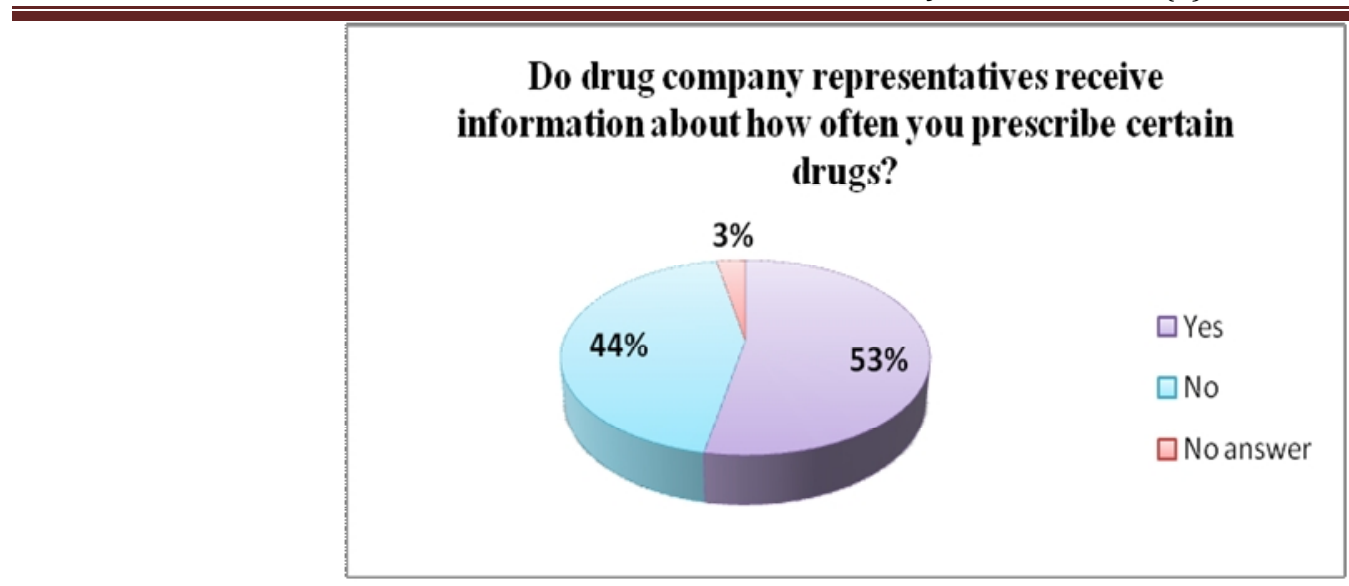

Figure 4: Information Received by Representatives Regarding their Prescribing Drugs

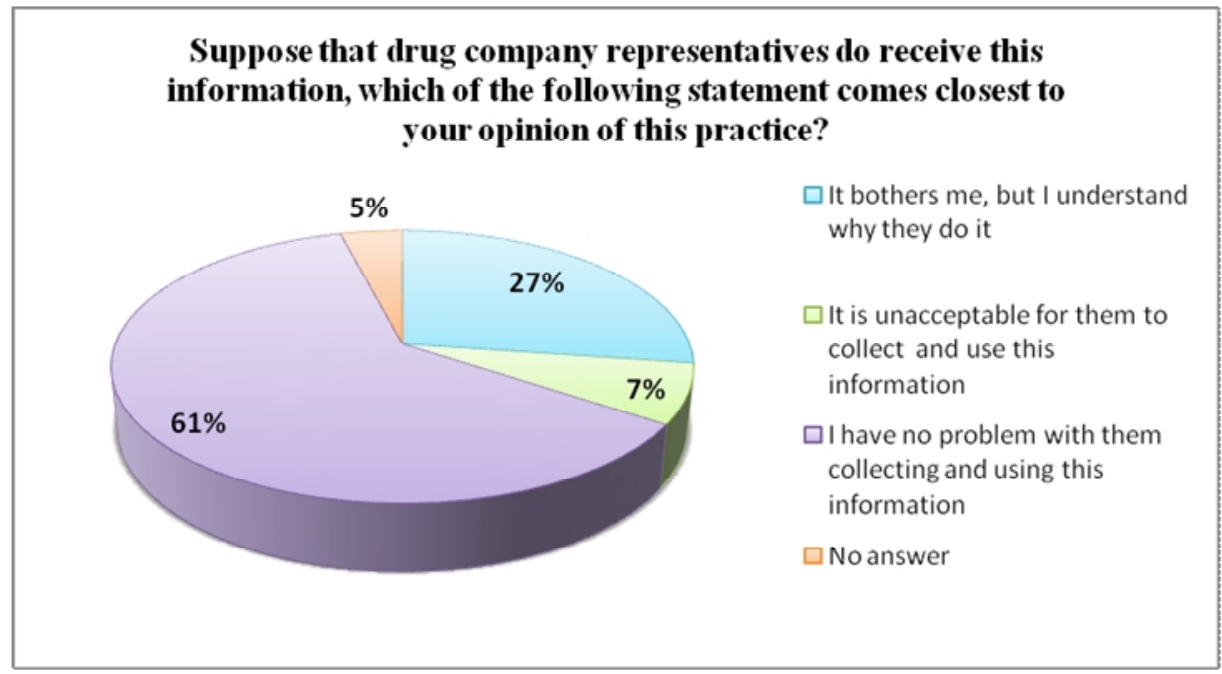

Figure 5: Opinion about Information Collection

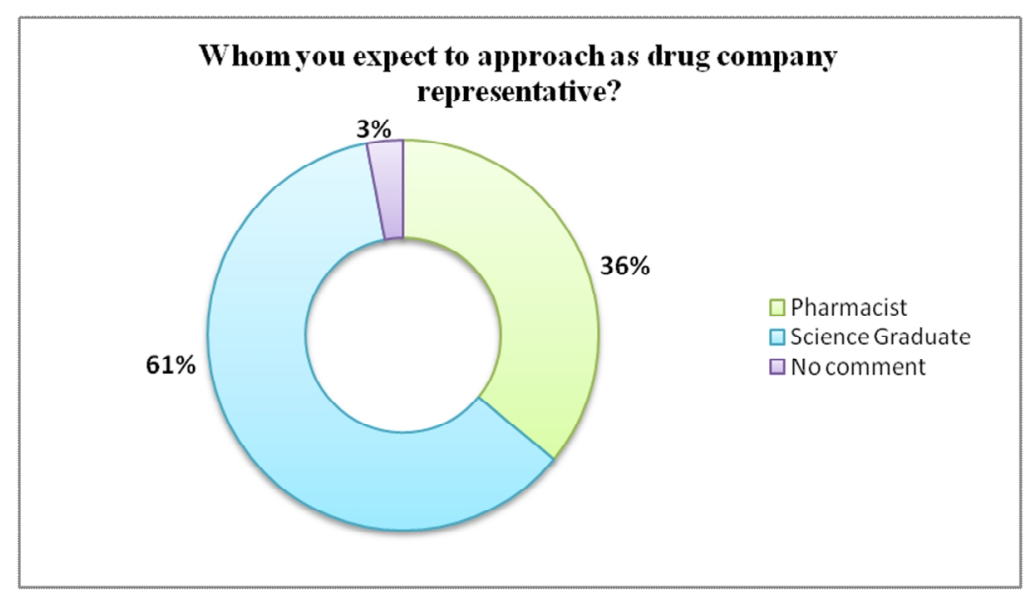

Figure 6: Expected Qualification of Medical Representative 


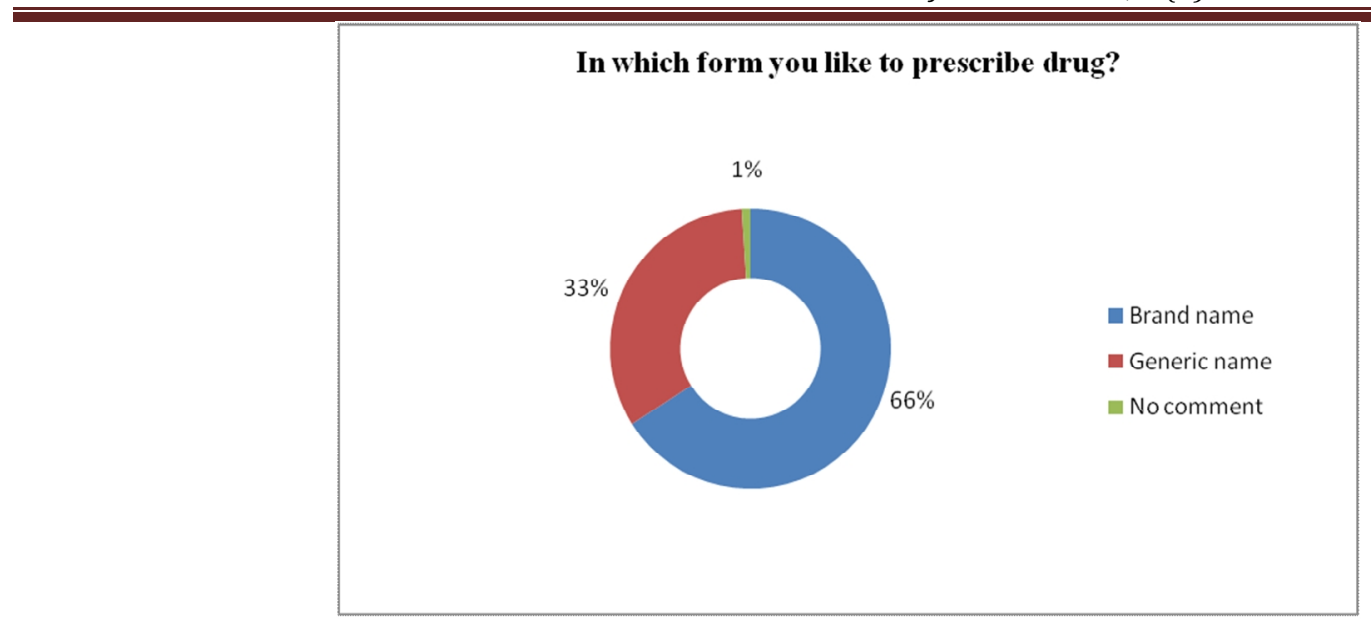

Figure 7: Type of Drug Name Physician Prescribe

Physicians also preferred science graduates over pharmacists to work as medical promotional representatives, which is totally opposite what is practiced in the developed countries. The reason is found to be the fact that, the pharmacy graduates are reluctant to come in this field as because of poor remuneration in comparison to their standard. But it is now a high time that the pharmacy graduates should come forward to enter the field of pharmaceutical product promotion. From the view of maximum physicians (72\%), the informations provided by the drug companies were somewhat useful. In practice, it was found that, the informations those the drug companies gathered about a new drug were often accurate in data but they also sometimes exaggerated the informations when they presented these before a physician. Our suggestion from this research work to this point is that, the pharmaceutical companies should focus more on the well being of health care system of the country alongside their business profit. They will definitely visit the physicians and other personnel's involved in healthcare system but at the same time they should also adopt the oath of "anti-bribery and anti-corruption" as they deal with the most delicate product of human health care.

\section{REFERENCES}

1. Moynihan R. Who pays for the pizza, Redefining the relationships between and drug companies. BMJ 2003; 326: 1193-1196. http://dx.doi. org/10.1136/bmj.326.7400.1189

2. Campbell EG, Gruen RL, Mountford J, Miller LG, Cleary PD, Blumenthal D. A national survey of Physicians-Industry relationships. N Engl J Med 2007; 356: 1742- 50. http://dx.doi.org/10.1056 /NEJMsa064508 PMid:17460228

3. Gonul FF, Carter F, Petrova E, Srinivasan K. Promotion of prescription drugs and its impact on physicians' choice behavior. J Marketing 2001; 65: 79-90. http://dx.doi.org/10.1509/jmkg.65.3.79.18329

4. Lexchin J. What information do physicians receive from pharmaceutical representatives, Can Fam Physician 1997; 43: 941-5. PMid:9154366 PMCid:PMC2255515

5. Liu SS. A comparison of pharmaceutical promotional tactics between Hong Kong and China. J Business and Industrial Marketing 1995; 10: 34-43. http://dx.doi.org/10.1108/08858629510081577
6. Wazana A. Physicians and the pharmaceutical industry, is a gift ever just a gift, JAMA 2000; 283: 373-80. http://dx.doi.org/10.1001/jama. 283.3.373 PMid:10647801

7. Pitt L, Nel D. Pharmaceutical promotion tools - Their relative importance. European. J Marketing 1988; 22: 7-14. http://dx.doi.org/ 10.1108/EUM0000000005281

8. Streiner DL, Norman GR. Health Measurement Scales -A practical guide to their development and use. Oxford: Oxford University Press; $2^{\text {nd }}$ ed; 2001. PMCid:PMC80816

9. Berkeley JS, Richardson IM. Drug usage in general practice: an analysis of the drugs prescribed by a sample of the doctors participating in the 1969-70 North-east Scotland work-load study. J R Coll Gen Pract 1973; 23(128): 155-161. PMid:4768139 PMCid:PMC2156916

10. Chinburapa V, Larson LN, Brucks M, Draugalis J, Bootman JL, Puto CP. Physician prescribing decisions: the effects of situational involvement and task complexity on information acquisition and decision making. Soc Sci Med 1993; 36(11): 1473-1482. http://dx. doi.org/10.1016/0277-9536(93)90389-L

11. Britten N, Brant S, Cairns A, et al. Continued prescribing of inappropriate drugs in general practice. J Clin Pharm Ther 1995; 20(4): 199-205. http://dx.doi.org/10.1111/j.1365-2710.1995.tb00649.x PMid:8557783

12. Mc Gavock HK, Wilson Davis K, Connolly JP. Repeat prescribing management - a cause for concern, Br J Gen Pract 1999; 49(442): 343347.

13. Buusman A, Kragstrup J, Andersen M. General practitioners choose within a narrow range of drugs when initiating new treatments: a cohort study of cardiovascular drug formularies. Eur J Clin Pharmacol 2005; 61(9): 651-656. http://dx.doi.org/10.1007/s00228-005-0973-y PMid: 16187132

14. Levine Taub AA, Kolotilin A, Gibbons RS, Berndt ER. The National Bureau of Economics. The diversity of concentrated prescribing behavior: an application to antipsychotics. NBER working paper no. 16823. http://www.nber.org/papers/w16823. November 11, 2011. Accessed March 31, 2011.

15. Frank RG, Zeckhauser RJ. Custom-made versus ready-to-wear treatments: behavioral propensities in physicians' choices. J Health Econ 2007; 26(6): 1101-1127. http://dx.doi.org/10.1016/j.jhealeco.2007.08.00 2 PMid: 18031852

\section{Cite this article as:}

Mir Monir Hossain, Sumaiya Kawsar, Tasmuna Tamrin Tanmy and Abu Yousuf. Assessment of influencing factors on prescription practices of physicians in Bangladesh. Int. Res. J. Pharm. 2013; 4(8):112-116 http://dx.doi.org/10.7897/2230-8407.04819 